\title{
PENGARUH DOSIS PUPUK KANDANG SAPI DAN MIKORIZA TERHADAP PERTUMBUHAN TANAMAN JAGUNG (Zea mays L.)
}

\section{The Effect Of Cow Manure and Mycorrhizae Doses on The Growth Of Maize (Zea mays L.)}

\author{
Qoirul Umam, Wiyono*, Setie Harieni, Daryanti dan Agus Budiyono \\ Program Studi Agroteknologi, Fakultas Petanian, Universitas Tunas Pembangunan \\ Jl. Balekambang Lor No.1, Manahan, Surakarta, Jawa Tengah \\ *Corresponding author: mp.wiyono@yahoo.com
}

\begin{abstract}
In Indonesia, maize is the second important food crop after rice. Corn is a potential raw material for the food industry, processed products for home industries, as well as feed, so that the need continues to increase. Meanwhile, maize production is currently not sufficient to meet the needs, so the shortage is still met from imports. This study aims to determine the effect of cow manure and mycorrhizal doses on the growth of maize (Zea mays.L). The research was conducted in Gejugan Village, Andong District, Boyolali Regency, with a height of $154 \mathrm{~m}$ above sea level on the Grumusol soil type. This study used a completely randomized block design (RAKL) with two treatment factors, namely cow manure dosage factors $(0,10,20$, and 30 tonnes / ha) and mycorrhizae $(0,5,10 \mathrm{~g} /$ plant) with 3 replications. The results showed that the dose of cow manure affected the growth of maize plants, while the mycorrhizal dose only affected the growth of corn plant roots. The interaction effect of cow manure dose with mycorrhizae occurred on root growth of corn plants. The best maize growth was obtained in the combination of 30 ton / ha manure dose treatment with $10 \mathrm{~g} /$ plant mycorrhizae which produced the highest dry weight of stover $(97.39 \mathrm{~g})$, and the lowest dry weight $(61.00 \mathrm{~g})$ was obtained in the treatment without cow manure. and mycorrhizae.
\end{abstract}

Key words: corn, cow manure, mycor

\begin{abstract}
ABSTRAK
Di Indonesia jagung merupakan tanaman pangan penting ke dua setelah padi. Jagung merupakan bahan baku potensial untuk industri pangan, produk olahan industri rumah tangga, maupun pakan, sehingga kebutuhannya terus meningkat. Sementara produksi jagung saat ini belum dapat mencukupi kebutuhan sehingga kekurangannya masih dipenuhi dari impor. Penelitian ini bertujuan untuk mengetahui pengaruh dosis pupuk kandang sapi dan mikoriza terhadap pertumbuhan tanaman jagung (Zea mays.L). Penelitian dilaksanakan di Desa Gejugan Kecamatan Andong Kabupaten Boyolali dengan ketinggihan tempat $154 \mathrm{~m}$ dpl pada jenis tanah Grumusol. Penelitian ini menggunakan Rancangan Acak Kelompok Lengkap (RAKL) dengan dua factor perlakuan yaitu faktor dosis pupuk kandang sapi $(0,10,20$, dan 30 ton/ha) dan mikoriza $(0,5,10 \mathrm{~g} / \operatorname{tanaman})$ dengan 3 kali ulangan. Hasil penelitian menunjukkan bahwa dosis pupuk kandang sapi mempengaruhi pertumbuhan tanaman jagung, sedangkan dosis mikoriza hanya mempengaruhi pertumbuhan akar tanaman jagung. Pengaruh interaksi dosis pupuk kandang sapi dengan mikoriza terjadi pada pertumbuhan perakaran tanaman jagung. Pertumbuhan jagung terbaik diperoleh pada kombinasi perlakuan dosis pupuk kandang 30 ton/ha dengan mikoriza $10 \mathrm{~g} / \mathrm{tanaman}$ yang menghasilkan berat kering brangkasan tertinggi $(97,39 \mathrm{~g})$, dan berat kering brangkasan terendah $(61,00 \mathrm{~g})$ diperoleh pada perlakukan tanpa pupuk kandang sapi maupun mikoriza.
\end{abstract}

Kata kunci : jagung, pupuk kandang sapi, mikoriza

\section{PENDAHULUAN}

Di Indonesia jagung merupakan tanaman pangan penting ke dua setelah padi. Jagung merupakan bahan baku potensial untuk industri pangan, produk olahan industri rumah tangga, maupun pakan, sehingga kebutuhannya terus meningkat. Produksi jagung Indonesia tahun 2018 kembali melonjak hingga mencapai 30 
This is Under CC BY SA Licence

juta ton namun produksi jagung tersebut belum dapat mencukupi kebutuhan sehingga kekurangannya masih dipenuhi dari impor. Berdasarkan catatan BPS, data impor jagung pada 2018 mencapai 737.228 ton dari tiga negara yakni Argentina sebanyak 326.580 ton, Brasil sebesar 222.578 ton, dan Amerika Serikat sebesar 186.142 ton (Imas Damayanti dan Nidia Zuraya, 2019)

Salah satu kendala yang menyebabkan produksi jagung tidak dapat optimal karena sebagian besar budidaya jagung diusahakan di lahan kering (Abdurachman, A. A., Dariah, dan A. Mulyani, 2008). Pada umumnya lahan kering memiliki status kesuburan tanah yang rendah, yaitu dengan kandungan bahan organik kurang dari $2 \%$, padahal untuk memperoleh produktivitas optimal dibutuhkan bahan organik $>2,5 \%$ (Sudiarso, 2007).

Penggunaan pupuk organik pada lahan kering perlu dilakukan selain untuk menambah unsur hara juga dapat meningkatkan kemampuan menahan air karena sumber air pada lahan kering terbatas dari air hujan. Selain itu pengunaan pupuk hayati pada lahan kering sangat diperlukan untuk mempermudah air dan unsur hara dapat diserap tanaman. Pupuk hayati adalah pupuk yang mengandung mikroorganisme yang mempunyai peran positif bagi tanaman. Penggunaan pupuk hayati dapat mendekomposisi bahan organik sehingga unsur hara menjadi tersedia bagi tanaman. Pupuk hayati merupakan inokulan berbahan aktif mikroorganisme hidup yang berfungsi menambat hara tertentu atau memfasilitasi tersedianya hara dalam tanah bagi tanaman (Simanungkalit, 2006).

Pupuk kandang sapi yang umumnya cukup tersedia di wilayah lahan kering perlu dimanfaatkan untuk meningkatkan potensi lahan. Penggunaan pupuk kandang yang dikombinasikan dengan pemberian pupuk hayati merupakan alternatif solusi untuk meningkatkan potensi lahan kering. Penggunaan pupuk hayati yang berupa Mikoriza dapat mengefisienkan penyerapan air dan unsur hara oleh akar tanaman. Mikoriza merupakan simbiose mutualisme antara jamur dan sistem perakaran tanaman tingkat tinggi. Mikoriza dapat meningkatkan penyerapaan unsur hara makro dan beberapa unsur hara mikro. Akar tanaman yang bermikoriza dapat menyerap unsur hara dalam bentuk terikat dan tidak tersedia bagi tanaman. Selain itu Mikoriza juga dapat berfungsi sebagai pelindung biologi bagi terjadinya infeksi patogen akar (Davamani, 2010).

Menurut Gange (2000) bahwa akar tumbuhan yang bersimbiosis dengan Cendawan Mikoriza arbuskular (CMA) lebih efisien dalam penyerapan air dan unsur hara dibandingkan dengan akar tumbuhan yang tidak bersimbiosis dengan Cendawan Mikoriza arbuskular (CMA). Selain itu akar yang mempunyai mikoriza dapat menyerap unsur hara dalam bentuk terikat dan yang tidak tersedia bagi tanaman. Hifa eksternal pada mikoriza dapat menyerap unsur fosfat dari dalam tanah dan segera diubah menjadi senyawa poli fosfat. Senyawa polifosfat kemudian kedalam hifa dan dipecah menjadi fosfat organik yang dapat diserap oleh sel tanaman. Efisiensi pemupukan $\mathrm{P}$ sangat jelas meningkat dengan penggunaan mikoriza (Dewi, 2007).

Penambahan pupuk kandang sapi dan pupuk hayati berupa Mikoriza pada lahan kering merupakan sesuatu solusi yang menarik dipertimbangkan, namun sejauh mana dosis pupuk kandang sapi dan mikoriza berpengaruh terhadap pertumbuhan tanaman jagung perlu dikaji lebih jauh.

Kajian mengenai pengaruh dosis pupuk kandang sapi maupun dosis Mikoriza terhadap pertumbuhan jagung telah dilakukan. Hasil penelitian Juna Rezekinta Sitepu (2018 ) menunjukkan bahwa pemberian pupuk kandang sapi 30 ton/ha pada tanaman jagung meningkatkan tinggi, diameter batang, luas daun, indeks luas daun, bobot segar akar. Hasil penelitian Bayu Agung Nugroho (2020) menunjukkan bahwa pemberian (30 ton/ha) pupuk kandang sapi meningkatkan tinggi, jumlah daun, panjang tongkol, diameter tongkol, jumlah tongkol, dan berat tongkol.

Penelitian ini bertujuan untuk mengetahui pengaruh dosis pupuk kandang sapi 


\section{JURNAL ILMIAH AGRINECA \\ ISSN : 2721-074X (Online) - 2301-6698 (Print) \\ Available on : http://ejournal.utp.ac.id/index.php/AFP/index}

This is Under CC BY SA Licence

dan pupuk hayati mikoriza serta interaksinya terhadap pertumbuhan jagung. Hasil penelitian ini diharapkan bisa menjadi informasi yang penting bagi masyarakat dalam meningkatkan pertumbuhan tanaman jagung.

\section{METODE PELAKSANAAN}

Penelitian dilaksanakan di Dusun Gejugan, Desa Pelemrejo, Kecamatan Andong, Kabupaten Boyolali, ketinggian tempat $154 \mathrm{~m}$ dpl, dengan jenis tanah Grumusol. Bahan-bahan yang digunakan adalah benih jagung hibrida varietas P36 Bekisar dari PT. Dupont Malang, pupuk kandang sapi, air, mikoriza, pestisida nabati.

Penelitian ini menggunakan Rancangan Acak Kelompok Lengkap (RAKL) faktorial $4 \times 3$ dengan tiga ulangan. Faktor I adalah faktor dosis pupuk kandang sapi $(\mathrm{P})$ yang terdiri atas 4 taraf yaitu $\mathrm{P} 0=0$ ton/ha $(0$ $\mathrm{kg} /$ petak) ; $\mathrm{P} 1=10$ ton $/$ ha $(4,5 \mathrm{~kg} /$ petak $), \mathrm{P} 2=$
20 ton $/ \mathrm{ha}(9 \mathrm{~kg} /$ petak $), \quad \mathrm{P} 3=30$ ton $/ \mathrm{ha}(13,5$ $\mathrm{kg} /$ petak) ; Faktor II adalah faktor dosis mikoriza (M) terdiri atas 3 taraf, M0 $=0$ $\mathrm{g} /$ tanaman, $\quad \mathrm{M} 1=5 \mathrm{~g} / \mathrm{tanaman}, \mathrm{M} 2=10$ g/tanaman; sehingga terdapat 12 kombinasi perlakuan dan 36 satuan percobaan. Data hasil pengamatan dianalisis dengan ANOVA (Analysis of Varian) untuk mengetahui pengaruh perlakuan. Apabila ada pengaruh nyata dilakukan uji lanjut dengan uji Duncan Multiple Range Test (DMRT) pada taraf kepercayaan $5 \%$.

\section{HASIL DAN PEMBAHASAN}

\section{Pertumbuhan Tanaman Jagung}

Pertumbuhan tanaman Jagung diamati dari parameter tinggi tanaman, jumlah daun, berat segar tanaman, berat kering tanaman, berat segar akar, volume akar, panjang akar. Analisis sidik ragam terhadap parameter pertumbuhan disajikan pada tabel 1 .

Tabel 1. Hasil sidik ragam pengaruh dosis pupuk kandang sapi dan pupuk hayati Mikoriza terhadap pertumbuhan jagung

\begin{tabular}{|c|c|c|c|c|}
\hline \multirow[t]{2}{*}{ No } & \multirow[t]{2}{*}{ Parameter } & \multicolumn{3}{|c|}{ Sumber keragaman } \\
\hline & & $\mathrm{P}$ & $\mathrm{M}$ & $\mathrm{PxM}$ \\
\hline 1. & Tinggi Tanaman $(\mathrm{cm})$ & $* *$ & ns & ns \\
\hline 2. & Jumlah daun & $* *$ & ns & ns \\
\hline 3. & Brangkasan segar tanaman (g) & $* *$ & ns & ns \\
\hline 4. & Brangkasan kering tanaman (g) & $* *$ & ns & ns \\
\hline 5. & Berat segar akar (g) & $* *$ & $*$ & $*$ \\
\hline 6. & Volume akar (mm) & $* *$ & $* *$ & $*$ \\
\hline 7. & Panjang akar $(\mathrm{cm})$ & $* *$ & $* *$ & $*$ \\
\hline
\end{tabular}

Sumber : Analisis data primer

Keterangan : ** berbeda sangat nyata, * berbeda nyata , ns : tidak berbeda nyata

\section{Tinggi tanaman}

Pemberian pupuk kandang sapi ternyata memberikan pengaruh sangat nyata terhadap pertumbuhan tinggi tanaman jagung, namun pemberian pupuk hayati mikoriza maupun interaksinya dengan pupuk kandang ternyata tidak memberikan pengaruh yang nyata (Tabel 1). Hal ini menunjukkan bahwa perbedaan dosis pupuk kandang sapi yang dicobakan menyebabkan perbedaan tinggi tanaman jagung. Hasil Uji Duncan 5\% terhadap tinggi tanaman akibat perbedaan perlakuan dosis pupuk kandang sapi menunjukkan bahwa pemberian dosis pupuk kandang sapi sebanyak 30 ton/ha mampu meningkatkan pertumbuhan tinggi tanaman jagung secara signifikan (Tabel 2) 


\section{JURNAL ILMIAH AGRINECA \\ ISSN : 2721-074X (Online) - 2301-6698 (Print) \\ Available on : http://ejournal.utp.ac.id/index.php/AFP/index}

This is Under CC BY SA Licence

Tabel 2. Uji Duncan Multiple Range Test 5\% terhadap pertumbuhan tanaman jagung akibat perlakuan dosis pupuk kandang sapi dan mikoriza

\begin{tabular}{|c|c|c|c|c|c|c|c|c|}
\hline \multirow[t]{2}{*}{ Perlakuan } & \multicolumn{8}{|c|}{ Parameter pertumbuhan } \\
\hline & $\begin{array}{l}\text { Tinggi } \\
\text { tanaman } \\
(\mathrm{cm})\end{array}$ & $\begin{array}{l}\text { Jumlah } \\
\text { daun } \\
\text { (helai) }\end{array}$ & $\begin{array}{l}\text { Berat } \\
\text { tanaman } \\
(\mathrm{g})\end{array}$ & segar & $\begin{array}{l}\text { Berat kering } \\
\text { tanaman } \\
(\mathrm{g})\end{array}$ & $\begin{array}{l}\text { Berat akar } \\
\text { (g) }\end{array}$ & $\begin{array}{l}\text { Panjang akar } \\
(\mathrm{cm})\end{array}$ & $\begin{array}{l}\text { Volume } \\
\text { akar } \\
(\mathrm{mm})\end{array}$ \\
\hline \multicolumn{9}{|c|}{ Pupuk kandang sapi (P) } \\
\hline P0 & $198,52 \mathrm{a}$ & $10,02 \mathrm{a}$ & $223,19 \mathrm{a}$ & & $64,07 \mathrm{a}$ & $74,00 \mathrm{a}$ & $39,41 \mathrm{a}$ & $51,11 \mathrm{a}$ \\
\hline $\mathrm{P} 1$ & $212,69 \mathrm{ab}$ & $10,46 \mathrm{a}$ & $254,57 \mathrm{ab}$ & & $79,35 \mathrm{ab}$ & $84,46 \mathrm{ab}$ & $41,20 \mathrm{a}$ & $55,93 \mathrm{ab}$ \\
\hline $\mathrm{P} 2$ & $219,56 \mathrm{ab}$ & $11,61 \mathrm{ab}$ & $255,93 \mathrm{ab}$ & & $80,07 \mathrm{ab}$ & $85,15 \mathrm{ab}$ & $45,33 \mathrm{a}$ & $56,02 \mathrm{ab}$ \\
\hline P3 & $226,33 \mathrm{~b}$ & $12,20 \mathrm{~b}$ & $301,00 \mathrm{~b}$ & & $94,37 \mathrm{~b}$ & $96,43 \mathrm{~b}$ & $53,26 \mathrm{~b}$ & $64,54 \mathrm{~b}$ \\
\hline \multicolumn{9}{|c|}{ Mikoriza $(\mathrm{M})$} \\
\hline M0 & 211,97 & 10,92 & 252,81 & & 77,67 & $80,59 a$ & $42,07 \mathrm{a}$ & $52,99 \mathrm{a}$ \\
\hline M1 & 214,83 & 11,08 & 260,67 & & 78,47 & $83,46 \mathrm{ab}$ & $42,14 \mathrm{a}$ & $55,97 \mathrm{ab}$ \\
\hline M2 & 216,01 & 11,22 & 262,54 & & 82,26 & $90,83 \mathrm{~b}$ & $50,19 \mathrm{~b}$ & $65,74 \mathrm{~b}$ \\
\hline \multicolumn{9}{|c|}{ Kombinasi perlakuan (PxM) } \\
\hline P0M0 & 194 & 10,06 & 220,89 & & 61,00 & $60,11 \mathrm{a}$ & $36,78 \mathrm{a}$ & $46,67 \mathrm{a}$ \\
\hline P0M1 & 205,56 & 10,17 & 226,33 & & 62,61 & $76,50 \mathrm{ab}$ & $39,06 \mathrm{ab}$ & $53,61 \mathrm{abc}$ \\
\hline P0M2 & 196 & 9,83 & 222,33 & & 68,61 & $85,39 \mathrm{abc}$ & $42,39 a b$ & $53,06 \mathrm{abc}$ \\
\hline P1M0 & 219,06 & 10,17 & 243,55 & & 74,83 & $77,72 \mathrm{ab}$ & $36,89 \mathrm{a}$ & $46,94 \mathrm{a}$ \\
\hline P1M1 & 218,83 & 10,5 & 263,84 & & 82,11 & $83,05 \mathrm{bc}$ & $40,72 \mathrm{ab}$ & $56,11 \mathrm{abc}$ \\
\hline P1M2 & 220,78 & 10,72 & 260,39 & & 81,11 & $94,67 \mathrm{bc}$ & $46,00 \mathrm{bcd}$ & $65,00 \mathrm{bc}$ \\
\hline P2M0 & 223,06 & 11,33 & 259,89 & & 83,06 & $82,28 \mathrm{bc}$ & $41,89 a b$ & $51,94 \mathrm{ab}$ \\
\hline P2M1 & 206,28 & 11,56 & 242,83 & & 75,22 & $84,83 b c$ & $43,28 \mathrm{abc}$ & $51,67 \mathrm{ab}$ \\
\hline $\mathrm{P} 2 \mathrm{M} 2$ & 208,06 & 11,94 & 261,00 & & 81,94 & 86,26 bc & $50,83 \mathrm{~cd}$ & 64,17 bc \\
\hline P3M0 & 233,39 & 12,11 & 309,67 & & 93,95 & $90,39 \mathrm{bc}$ & 45,22 abcd & $62,50 \mathrm{bc}$ \\
\hline P3M1 & 222,56 & 12,11 & 286,89 & & 91,78 & $101,89 \mathrm{c}$ & $53,00 \mathrm{~d}$ & $66,39 \mathrm{c}$ \\
\hline P3M2 & 223,72 & 12,39 & 306,44 & & 97,39 & $97,00 \mathrm{bc}$ & $61,56 \mathrm{~d}$ & 64,72 bc \\
\hline
\end{tabular}

Keterangan : Angka-angka yang diikuti huruf yang sama pada kolom yang sama menunjukkan tidak berbeda nyata berdasarkan uji DMRT taraf $5 \%$.

\section{Jumlah daun}

Pemberian pupuk kandang sapi ternyata memberikan pengaruh sangat nyata terhadap pertumbuhan jumlah daun jagung, namun pemberian pupuk hayati mikoriza maupun interaksi dengan pupuk kandang ternyata tidak memberikan pengaruh yang nyata (Tabel 1). Hal ini menunjukkan bahwa perbedaan dosis pupuk kandang sapi yang dicobakan menyebabkan perbedaan jumlah daun tanaman jagung. Hasil Uji Duncan 5\% terhadap jumlah daun tanaman akibat perbedaan perlakuan dosis pupuk kandang sapi menunjukkan bahwa pemberian dosis pupuk kandang sapi sebanyak 30 ton/ha mampu meningkatkan pertumbuhan jumlah tanaman jagung secara signifikan (Tabel 2).

\section{Berat segar tanaman}

Pemberian pupuk kandang sapi ternyata memberikan pengaruh sangat nyata terhadap pertumbuhan berat segar tanaman jagung, namun pemberian pupuk hayati mikoriza maupun interaksinya dengan pupuk kandang ternyata tidak memberikan pengaruh yang nyata (Tabel 1). Hal ini menunjukkan bahwa perbedaan dosis pupuk kandang sapi yang dicobakan menyebabkan perbedaan berat segar tanaman jagung. Hasil Uji Duncan 5\% terhadap berat segar tanaman akibat perbedaan perlakuan dosis pupuk kandang sapi menunjukkan bahwa Pemberian dosis pupuk kandang sapi sebanyak 30 ton/ha mampu meningkatkan pertumbuhan berat segar tanaman jagung secara signifikan (Tabel 2)

\section{Berat kering tanaman}

Pemberian pupuk kandang sapi ternyata memberikan pengaruh sangat nyata terhadap pertumbuhan berat kering tanaman jagung, namun pemberian pupuk hayati mikoriza maupun interaksinya dengan pupuk kandang ternyata tidak memberikan pengaruh yang nyata 


\section{JURNAL ILMIAH AGRINECA \\ ISSN : 2721-074X (Online) - 2301-6698 (Print) \\ Available on : http://ejournal.utp.ac.id/index.php/AFP/index \\ This is Under CC BY SA Licence}

(Tabel 1) terhadap pertumbuhan berat kering tanaman jagung. Hal ini menunjukkan bahwa perbedaan dosis pupuk kandang sapi yang dicobakan menyebabkan perbedaan berat kering tanaman jagung. Hasil Uji Duncan 5\% terhadap berat kering tanaman akibat perbedaan perlakuan dosis pupuk kandang sapi menunjukkan bahwa Pemberian dosis pupuk kandang sapi sebanyak 30 ton/ha mampu meningkatkan pertumbuhan berat kering tanaman jagung secara signifikan (Tabel 2)

\section{Berat segar akar}

Pemberian pupuk kandang sapi, mikoriza, maupun interaksinya ternyata memberikan pengaruh nyata terhadap pertumbuhan berat segar akar jagung (Tabel 1). Hal ini menunjukkan bahwa perbedaan dosis pupuk kandang maupun mikoriza menyebabkan perbedaan perkembangan akar tanaman jagung sehingga berat segar akar jagung terdapat perbedaan yang signifikan. Hasil Uji Duncan 5\% terhadap berat segar akar akibat perbedaan pengaruh interaksi perlakuan dosis pupuk kandang sapi dan mikoriza menunjukkan bahwa pemberian pupuk kandang yang diberikan bersamaan dengan mikoriza dapat meningkatkan perkembangan akar jagung. Pemberian dosis pupuk kandang sapi 30 ton yang diberikan bersamaan dengan pemberian mikoriza $5 \mathrm{~g} /$ tanaman meningkatkan berat segar akar jagung secara signifikan (Tabel 2). Untuk mengetahui pengaruh interaksi dosis pupuk kandang dan mikoriza disajikan grafik berat segar akar.

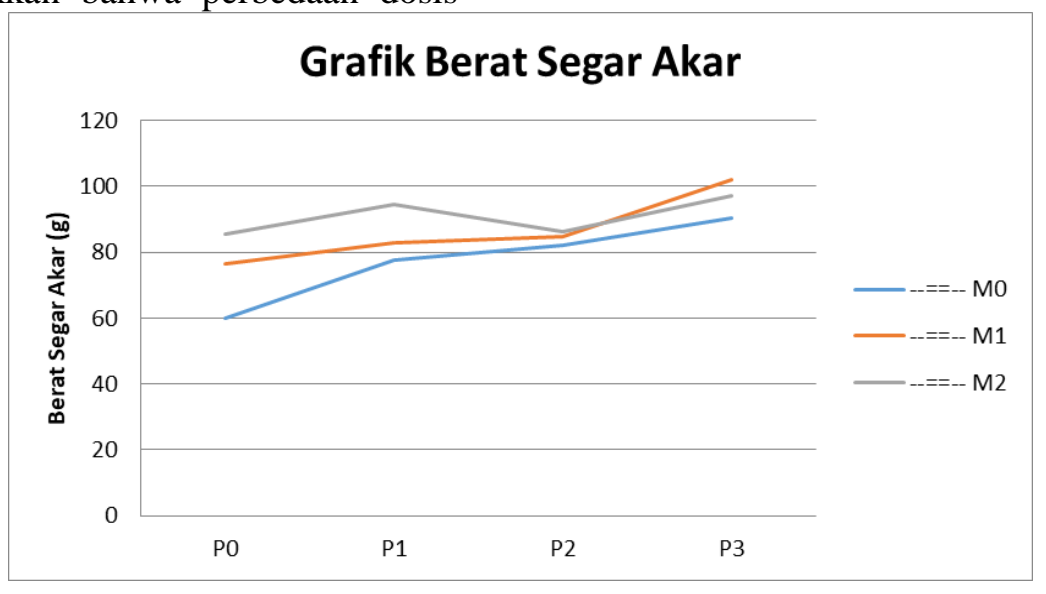

Gambar 1. Grafik Berat Segar Akar

Pada grafik di atas menunjukkan bahwa pemberian dosis pupuk kandang sapi 10 ton/ha yang diberikan bersamaan dengan $5 \mathrm{~g}$ mikoriza/tanaman $\left(\mathrm{P}_{1} \mathrm{M}_{1}\right) \quad$ ternyata meningkatkan berat segar akar tanaman jagung, namun setelah dosis pupuk kandang sapi dan mikoriza ditingkatkan menjadi 20 ton/ha dan 10 g mikoriza/tanaman $\left(\mathrm{P}_{2} \mathrm{M}_{2}\right)$ ternyata diperoleh berat segar akar yang lebih rendah. Berat segar akar tanaman jagung meningkat lagi setelah diberikan dosis pupuk kandang sapi ditingkatkan lagi menjadi 30 ton/ha dan $15 \mathrm{~g}$ mikoriza/tanaman $\left(\mathrm{P}_{3} \mathrm{M}_{3}\right)$. Sedangkan pada pemberian mikoriza $5 \mathrm{~g} /$ tanaman yang diberikan bersamaan dengan pupuk kandang sapi yang ditingkatkan $\left(\mathrm{P}_{1} \mathrm{M}_{1}\right),\left(\mathrm{P}_{2} \mathrm{M}_{1}\right),\left(\mathrm{P}_{3} \mathrm{M}_{1}\right)$ ternyata diperoleh berat segar akar tanaman jagung yang semakin meningkat.

\section{Volume akar}

Pemberian pupuk kandang sapi, mikoriza, maupun interaksinya ternyata memberikan pengaruh nyata terhadap pertumbuhan volume akar jagung (Tabel 1) Hal ini menunjukkan bahwa perbedaan dosis pupuk kandang maupun mikoriza menyebabkan perbedaan perkembangan akar tanaman jagung sehingga volume akar jagung terdapat perbedaan yang signifikan. Hasil Uji Duncan 5\% terhadap volume akar jagung akibat perbedaan pengaruh interaksi perlakuan dosis pupuk kandang sapi dan mikoriza menunjukkan bahwa pemberian pupuk kandang yang 


\section{JURNAL ILMIAH AGRINECA \\ ISSN : 2721-074X (Online) - 2301-6698 (Print) \\ Available on : http://ejournal.utp.ac.id/index.php/AFP/index}

This is Under CC BY SA Licence

diberikan bersamaan dengan mikoriza dapat meningkatkan perkembangan akar jagung. Pemberian dosis pupuk kandang sapi 30 ton yang diberikan bersamaan dengan pemberian mikoriza $5 \mathrm{~g} /$ tanaman meningkatkan volume akar jagung secara signifikan (Tabel 2)

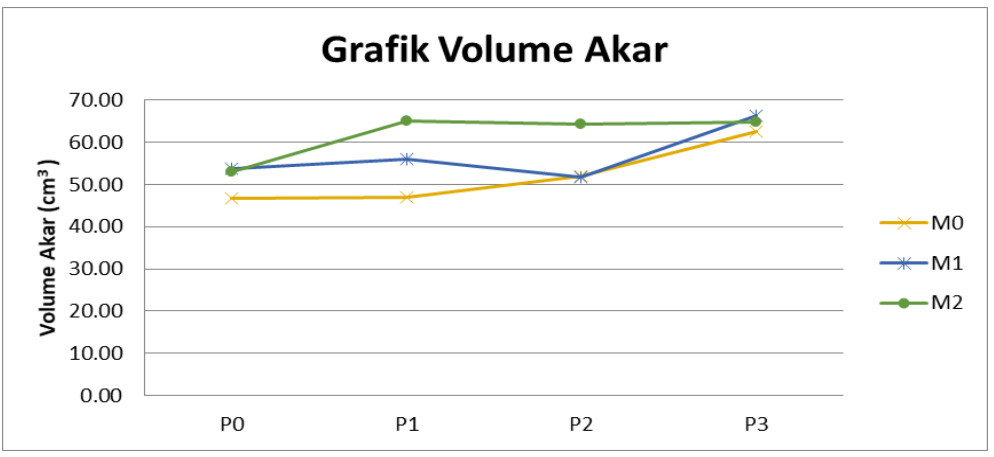

Gambar 2. Grafik Volume Akar

Pada grafik di atas menunjukkan bahwa volume akar tanaman jagung meningkat setelah diberikan pupuk kandang sapi 10 ton/ha bersamaan dengan $5 \mathrm{~g}$ mikoriza/tanaman $\left(\mathrm{P}_{1} \mathrm{M}_{1}\right)$ maupun bersamaan dengan $10 \mathrm{~g}$ mikoriza/tanaman $\left(\mathrm{P}_{1} \mathrm{M}_{2}\right)$ dan selanjutnya tetap meskipun dosis pupuk kandang sapi ditingkatkan $\left(\mathrm{P}_{2} \mathrm{M}_{2}, \mathrm{P}_{3} \mathrm{M}_{2}\right)$, sebaliknya pada dosis mikoriza $5 \mathrm{~g} /$ tanaman volume akar jagung meningkat setelah dosis pupuk kandang sapi ditingkatkan menjadi 30 ton/ha $\left(\mathrm{P}_{3} \mathrm{M}_{1}\right)$.

\section{Panjang akar}

Pemberian pupuk kandang sapi, mikoriza, maupun interaksinya ternyata memberikan pengaruh nyata terhadap pertumbuhan panjang akar jagung (Tabel 1). Hal ini menunjukkan bahwa perbedaan dosis pupuk kandang maupun mikoriza menyebabkan perbedaan perkembangan akar tanaman jagung sehingga panjang akar jagung terdapat perbedaan yang signifikan. Hasil Uji Duncan 5\% terhadap panjang akar akibat perbedaan pengaruh interaksi perlakuan dosis pupuk kandang sapi dan mikoriza menunjukkan bahwa pemberian pupuk kandang yang diberikan bersamaan dengan mikoriza dapat meningkatkan perkembangan akar jagung. Pemberian dosis pupuk kandang sapi 30 ton yang diberikan bersamaan dengan pemberian mikoriza $5 \mathrm{~g} /$ tanaman meningkatkan panjang akar jagung secara signifikan (Tabel 2)

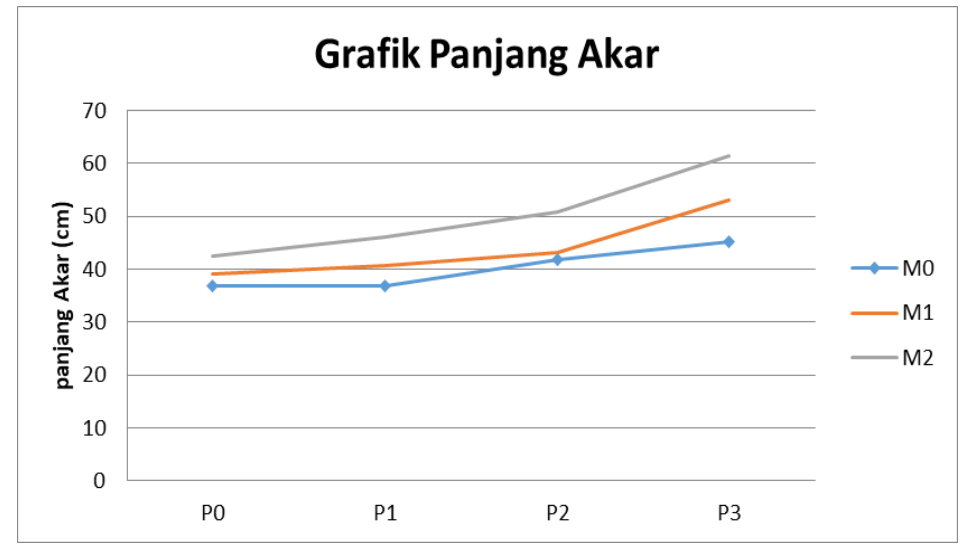

Gambar 3. Grafik Panjang Akar 


\section{JURNAL ILMIAH AGRINECA \\ ISSN : 2721-074X (Online) - 2301-6698 (Print) \\ Available on : http://ejournal.utp.ac.id/index.php/AFP/index}

This is Under CC BY SA Licence

Pada grafik di atas menunjukkan bahwa panjang akar tanaman jagung yang meningkat dengan bertambahnya dosis pupuk kandang sapi dan mikoriza yang diberikan $\left(\mathrm{P}_{0} \mathrm{M}_{0}, \mathrm{P}_{1} \mathrm{M}_{1}\right.$, $\mathrm{P}_{2} \mathrm{M}_{2}, \mathrm{P}_{3} \mathrm{M}_{3}$ ). Peningkatan pertumbuhan jagung akibat pemberian pupuk kandang sapi dan mikoriza terjadi karena terjadinya perubahan sifat fisik tanah menjadi lebih gembur akibat pemberian pupuk kandang sapi sehingga perakaran jagung lebih mudah menembus tanah untuk menyerap air dan unsur hara. Selanjutnya simbiose akar tanaman jagung dengan mikoriza yang terjadi akan menambah kemampuan tanaman menyerap air dan unsur hara. Hal ini sesuai dengan pendapat Farida (2011) bahwa pemberian pupuk kandang sapi dan mikoriza dapat meningkatkan efektifitas penyerapan unsur hara dan air.

\section{KESIMPULAN}

Dosis pupuk kandang sapi mempengaruhi pertumbuhan tanaman jagung yang meliputi tinggi tanaman, jumlah daun, berat segar tanaman, berat kering tanaman, berat akar, volume akar, dan panjang akar. Dosis pupuk hayati mikoriza mempengaruhi berat akar, volume akar, dan panjang akar tanaman jagung, tetapi tidak mempengaruhi pertumbuhan tinggi, jumlah daun, berat segar tanaman, dan berat kering tanaman. Pertumbuhan jagung terbaik yang menghasilkan berat kering brangkasan tertinggi, diperoleh pada perlakuan dosis pupuk kandang sapi 30 ton/ha dan mikoriza $10 \mathrm{~g} /$ tanaman $\left(\mathrm{P}_{3} \mathrm{M}_{2}\right)$ yaitu $97,39 \mathrm{~g}$.

\section{DAFTAR PUSTAKA}

Abdurachman, A., A. Dariah dan A. Mulyani. 2008. Strategi dan Teknologi Pengelolaan Lahan Kering Mendukung Pengadaan Pangan Nasional. Jurnal Litbang Pertanian 27(2):4349.

Bayu Agung Nugroho. 2020. Respon Pertumbuhan Dan Hasil Tanaman Jagung Ketan (Zea Mays Ceratina) Akibat Pemberian Berbagai
Takaran Pupuk Bokashi Kotoran Sapi. Universitas Tridinanti Palembang Palembang.

Davamani V. A,C. Lourduraj, R.P. Yogalakshmi and M. Velmurugan, 2010. Role of VAM in Nutrient Uptake of Crop Plants. dalam Devarajan Thangadurai Carlos Alberto Busso Mohamed Hijri, (eds), 2010. Mycorrhizal Biotechnology. Printed in India, in collaboration with Capital Publishing Company.

Dewi, R.I. 2007. Makalah Peran, Prospek dan Kendala dalam Pemanfaatan Endomikoriza. Fakultas Pertanian. Universitas Padjajaran. Bandung.

Farida, R. 2011. Pengaruh Pemberian Cendawan Mikoriza Arbuskula (CMA) dan Dosis Pupuk Kandang Sapi terhadap Pertumbuhan dan Produksi Jagung. IPB. Bogor. Gange, A. 2000. Arbuscular Mycorrhizal Fungi, Collembola and Plant Growth. Tree. 15:369372.

Gange, A. 2000. Arbuscular Mycorrhizal Fungi, Collembola and Plant Growth. Tree. 15:369372.

Husin, E.F. 2000. Cendawan Mikoriza Arbuskula. Fakultas Pertanian Universitas Andalas: Padang.

Juna Rezekinta Sitepu,Ferry Ezra T Sitepu. 2018. JurnalAgroekoteknologi FP USU E-ISSN No. 2337- 6597 Vol.6.No.1, Januari 2018 (6): 37 46

Simanungkalit, R. D. M., Didi, A. S., Rasti, S., Diah, S., \& Wiwik, H. (2006). Pupuk Organik dan Pupuk Hayati. Balai Besar Penelitian danPengembangan Sumberdaya Lahan Pertanian. Jawa Barat

Sudiarso. 2007. Pupuk organik dalam Sistem Pertanian Berkelanjutan. FP UB. Malang.

Wisnu Utomo, Murti Astriningrum, Yulia Eka Susilowati 2017. Pengaruh Mikoriza terhadap hasil tanaman jagung. Jurnal untidar. Vol 2, no 1 (2007).

Yonida Arinda Dwi. 2017. Jenis-jenis Tanaman Pangan. Agribisnis UGM. https://farming.id/jenisjenis-tanaman-pangan/. 10 Oktober 2018.

Yusnaini, S. 2009. Keberadaan Mikoriza Vesikular Arbuskular Pada Pertanaman Jagung yang diberi Pupuk Organik dan Anorganik jangka panjang. Tanah Trop. 14(3):253-256. 